\title{
Influence of particle size and total organic carbon on the distribution of polybrominated diphenyl ethers in landfill soils: assessment of exposure implications
}

\author{
E. Akortia ${ }^{1,2^{*}}$ (D, M. Lupankwa' and J. O. Okonkwo
}

\begin{abstract}
Background: The selection of soil fraction is an important influencing factor to accurately determine human exposure risk to toxic chemicals in the environment. The present study evaluated the concentrations of prevalent polybrominated diphenyl ethers (PBDEs) in different size fractions of soil from a landfill site and the factors that influence their distribution in the soils.

Method: Samples were fractionated into size fractions; between 150-250 and 45-150 $\mu \mathrm{m}$ (after initial sieving through a $250 \mu \mathrm{m}$ sieve) and, thereafter, PBDEs were extracted using a mixture of toluene-dichloromethane and subsequently cleaned with a multilayer silica gel/Pesticarb/sodium sulphate column and analysed using GC-MS.

Results: The sum of seven PBDE congeners (BDE-28, -47, -100, -99, -154, -153 and -183) ranged from 7.08 to $10.8 \mathrm{ng} \mathrm{g}^{-1}$ with a total median of $7.32 \mathrm{ng} \mathrm{g}^{-1}$, and from 7.00 to $8.77 \mathrm{ng} \mathrm{g}^{-1}$ with a total median of $7.21 \mathrm{ng} \mathrm{g}^{-1}$, corresponding to size fractions $150-250 \mu \mathrm{m}$ and $45-150 \mu \mathrm{m}$, respectively. BDE-183 was predominant in both soil fractions. A significant correlation was observed between $\sum_{7}$ PBDEs concentrations and total organic carbon (TOC), particularly for particle size $150-250 \mu \mathrm{m}\left(r^{2}=0.829, p<0.05\right)$.

Conclusion: The study revealed that PBDE concentrations did not automatically increase with decreasing particle size, and as such, PBDE-treated consumer goods and consequent abrasions of flame retardant-containing materials could be likely sources. The study also clarified that selecting soil fractions arbitrarily for exposure risk assessment may lead to inconclusive results. The study results, therefore, have important inferences for estimating flame retardant chemical exposure.
\end{abstract}

Keywords: PBDEs, Human exposure, TOC, Particle size, Soil, South Africa

\section{Introduction}

Polybrominated diphenyl ethers (PBDEs) are a group of industrial chemical compounds used as flame retardants (FRs) to inhibit the rate of accidental fires in order to save lives and properties from being gutted by flames. They are additive FRs incorporated in a wide range of consumer products such as electronic components, plastics, textiles, furnishing foam and fabrics for these

\footnotetext{
*Correspondence: Sericuk@yahoo.co.uk; eakortia@gmail.com

${ }^{1}$ Environmental Chemistry Research Group, Department of Environmental, Water and Earth Sciences, Tshwane University of Technology, Private Bag X680, Pretoria, South Africa

${ }^{2}$ Ghana Atomic Energy Commission, Radiation Protection Institute, Legon, P. O. Box LG 80, Accra, Ghana
}

products to meet fire safety requirements (Bergman et al. 2012). Despite the benefits of FRs, their use is problematic owing to their persistence, bio-accumulative tendencies and possible adverse effects on wildlife and humans, even in the arctic (Kajiwara and Takigami 2016). Meanwhile, environmental concerns have been raised about these compounds (Zhang et al. 2014). As a result of the adverse characteristics presented by PBDEs, their use has been regulated in several countries. For example, commercial penta-BDEs and octa-BDEs were banned in Europe, as well as some manufacturing companies in the USA have voluntarily phased out PBDE production in 2004 (Wang et al. 2016). 
PBDEs can be released into the surrounding environment during the production, usage and disposal of articles containing these chemical compounds. Once deposited, these chemicals tend to accumulate in soil for long periods of time (Cetin and Odabasi 2007).

Soil is recognized as significant role player in the overall global distribution and fate of persistent organic pollutants (POPs) such as PBDEs (Dušek et al. 2009). Therefore, information on the properties and characteristics of soil is imperative to better understand environmental contamination and air-soil exchange processes of POPs (Cousins et al. 1999).

Moreover, it has been shown that there is a strong relationship between soil organic carbon content and contaminant concentration (Liu et al. 2010). Though amorphous organic matter and carbonaceous geosorbents in soil may also play a critical role in the fate and distribution of PBDEs (Semple et al. 2013), the contributory influence of soil organic carbon is preponderant in controlling the sorption and desorption of weakly polar organic compounds through partitioning (Cousins et al. 1999; Nam et al. 2008). POPs may often bind to soil fractions that correlate with organic matter due to their hydrophobicity (Gustafsson et al. 1996; Pignatello 1998).

Over the past decades, there has been a massive increase in municipal and industrial solid waste due to increase in industrialisation and population. Whereas historical uses and releases of POPs such as PBDEs were associated with industrial applications and waste, a considerable proportion of POPs can be found in household consumer products and building materials (Weber et al. 2011). Consequently, the final point of these materials is often the open dumpsites or municipal solid waste landfills (Daso et al. 2012).

The Hatherley landfill site in Pretoria, which was identified for this study, is without geomembrane lining (Odusanya et al. 2009). Hence, it was considered to be prone to the formation and release of toxic POPs in waste items over time. There is also evidence that consumer products treated with brominated flame retardants (BFRs) can leach from landfills and contaminate the environment (Danon-Schaffer 2010; Odusanya et al. 2009). In view of this, the surface soil surrounding landfills could remain contaminated as a result of atmospheric transport and deposition phenomenon (DanonSchaffer 2010). This may also present exposure risk to humans, especially adults and children living in proximity to these areas. For some developing countries that rely almost exclusively on open dumps, research has demonstrated the association between POPs on contaminated sites and the impacts on humans living near the vicinity of these sites (Athanasiadou et al. 2008; Someya et al. 2010).
Previous investigations (Odusanya et al. 2009; Daso et al. 2012) indicated that landfill leachate may cause contaminants to infiltrate into the underlying soil if the geomembrane lining is compromised. Although reports on PBDEs in landfill leachates and sediments have been published (Danon-Schaffer et al. 2013; Daso et al. 2012; Odusanya et al. 2009; Osako et al. 2004), information on PBDEs in landfill soils is still scarce or scanty. With respect to contaminated soils in the present study, reference is made to the range of particle sizes for which exposure is likely to occur via ingestion (often accidental) and dermal absorption. For PBDEs, much like other chemicals, the main exposure routes are ingestion, inhalation and dermal absorption. However, accidental soil ingestion and dermal absorption are the major exposure routes for toxic chemicals present in soil or dust (Frederiksen et al. 2009; Jones-Otazo et al. 2005; Johson-Restrepo and Kannan 2009; Lorber 2008).

In terms of exposure assessment, soil particle size is an important factor (Cao et al. 2012). Nevertheless, earlier reports have shown that there is no clear trend for typical size distributions in soil or dust (Morawska and Salthammer 2003), although a previous study has demonstrated that soil-pollutant concentration generally increases with decrease in particle size (Mercier et al. 2011). Therefore, possible ingestion and hence, adherence of fine soil particles to the skin may vary with particle size (Cao et al. 2012; Mercier et al. 2011). According to Lewis et al. (1999), dust particles less than $100-200 \mu \mathrm{m}$ in diameter adhered more efficiently on the skin. In a Greek study (Mandalakis et al. 2009), atmospheric PBDE particle size distribution showed a distinct enrichment in smaller particles.

More so, there is lack of common agreement between pollutant distributions with respect to the selection of soil fractions. Hence, there is a need to advance research to determine the influence of soil size fractions on the distribution of pollutants and their associated risks. The study was, therefore, aimed at evaluating the effect of particle size distribution of prevalent PBDEs in landfill soils and the factors affecting the distribution, as well as their exposure implications.

\section{Methods/experimental}

The present study evaluated the concentrations and distribution of PBDEs with respect to particle sizes and the organic carbon content of soil samples from an unlined landfill site in the Gauteng province of the Republic of South Africa.

This is the first time this type of work was conducted using contaminated landfill cover soils in South Africa.

The aims of this study were to: 
1. Determine the composition of PBDE congeners in different size fractions of soil samples collected from Hatherley landfill site, and

2. Evaluate the factors that influence their distribution in the soil, as well as their exposure implications.

\section{Description of materials}

Pure standards $\left(1.2 \mathrm{~mL}\right.$ of $\left.50 \mathrm{mg} \mathrm{L}^{-1}\right)$ of each certified standard solutions of ten PBDEs congeners (BDEs- 28, $-47,-99,-100,-118,-154,-153,-183$ and 13C-BDEs-139, -77) used were purchased from Wellington Laboratories (Guelph, ON, Canada). Standard reference material for house dust SRM-2585 was purchased from the National Institute of Standards and Technology (Gaithersburg, MD, USA). Copper powder (99.98\%) from Saarchem (Pty) Ltd., Muldersdrift, South Africa, silica gel (100-200 mesh), sodium sulphate (purity 99.9\%), glass wool and HPLC grade solvents: hexane, acetone, dichloromethane (DCM) and toluene (Sigma-Aldrich, Chemie $\mathrm{GmbH}$, Steinheim, Germany), were purchased from Aston Manor, South Africa. Activated charcoal (Pesticarb) was purchased from Separations (Pty), South Africa. High purity nitrogen gas (99.999\% purity) was supplied by Afrox (Pty.), Pretoria, South Africa.

\section{Sampling and sample description}

Soil samples were collected at a depth of $0-10 \mathrm{~cm}$ from six different functional areas of the Hatherley landfill site in Pretoria, Gauteng province of South Africa (Fig. 1). At each point, triplicate samples were collected and pooled, homogenized and sub-sampled making a total of six pooled samples. For the purpose of sample description, the pooled sub-samples were labelled from S1 to S6 (i.e. $\mathrm{S} 1=$ recovered cell $1, \mathrm{~S} 2=$ recovered cell $2, \mathrm{~S} 3=$ buffer area; $100 \mathrm{~m}$ away from the cells, $\mathrm{S} 4=$ recycling area, $\mathrm{S} 5=$ active dumping area and $\mathbf{S 6}=$ receiving and sorting area). The soil samples were collected using a pre-cleaned stainless steel hand trowel, following the clearing and removal of debris and large pebbles and were subsequently wrapped in aluminium foil and transported to our laboratory and stored at $-20^{\circ} \mathrm{C}$ until processing and analysis.

\section{Sample treatment and analysis}

All soil samples used in the study were initially sieved through the $250 \mu \mathrm{m}$ stainless steel mesh followed by sequential sieving through two different sets of sieves; $150 \mu \mathrm{m}$ and $45 \mu \mathrm{m}$ mesh stacked on each other from top to bottom. Stainless steel plates were placed at the bottom and top for soil collection and covering, respectively, and the sieves were manually shaken for about 7$8 \mathrm{~min}$. What is more, the soil fractions representing the $0-45 \mu \mathrm{m}$ in diameter were lost as a consequence of the dry sieving and adherence to the preceding sieve. Thus, it could be estimated that the $0-45 \mu \mathrm{m}$ size fraction was virtually non-substantial, as it constituted an extremely small proportion $(\mathrm{ca}<1 \%)$ which we could not determine. All sieved soils were subsequently wrapped in aluminium foil and portions of each fraction weighed for the determination of total organic carbon (TOC) and PBDEs as well as particle size distribution using a particle size analyser.

Subsequently, each of the sieved (150-250 and 45$150 \mu \mathrm{m})$ soils were spiked with ${ }^{13} \mathrm{C}$-BDE-77 and ${ }^{13} \mathrm{C}$ BDE-139 and left to equilibrate for about an hour. The

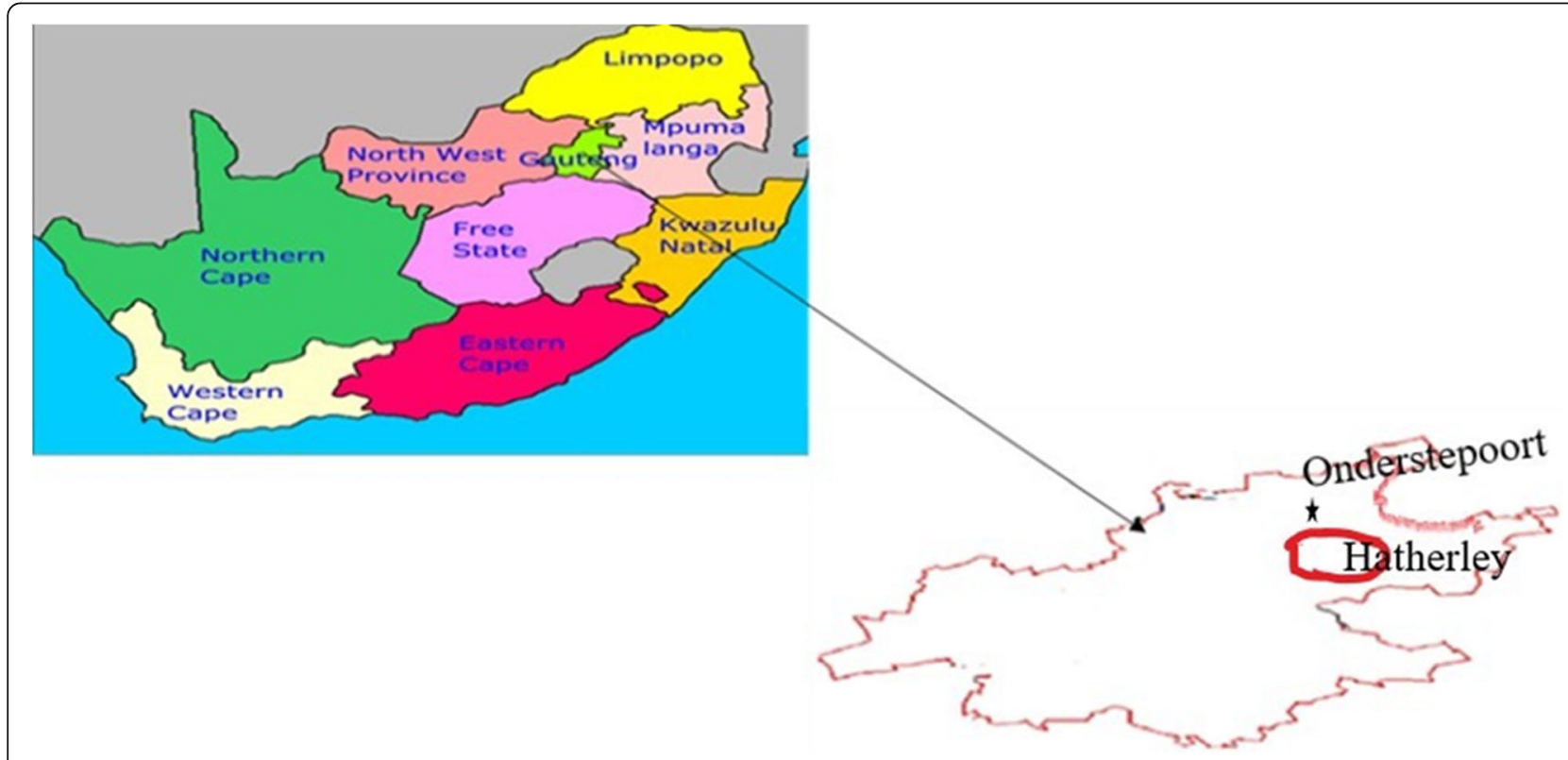

Fig. 1 Map of South Africa showing the location of Hatherley landfill site (circled in red) in the enlarged area 
spiked samples were then soaked in $20 \mathrm{~mL}$ DCM/toluene $(1: 1, v / v)$ in airtight $100 \mathrm{~mL}$ amber bottles. Sample extraction followed the method previously described by Olukunle et al. (2015) and Akortia et al. (2017) with minor modifications.

Briefly, about $5 \mathrm{~g}$ of each sample was weighed and ultrasonically extracted with $20 \mathrm{~mL}$ DCM/toluene (1:1, $v / v)$. An ultrasonic bath (Elmasonic S 40H, Germany), with a maximum power of $340 \mathrm{~W}$, was utilized and set at $40{ }^{\circ} \mathrm{C}$ in an extraction time of $30 \mathrm{~min}$ and the extracts were centrifuged at $1480 \times g$ for $4 \mathrm{~min}$. This process was repeated three times using fresh solvents in each batch and about $60 \mathrm{~mL}$ each of the extracts collected. The crude extracts were evaporated to $1 \mathrm{~mL}$ by a rotary evaporator (Buchi Rotavapor, R-210, Labotec, South Africa). The extracts were de-sulphurized by adding $2 \mathrm{~g}$ of activated copper granules, and purified by a mixed column chromatography following a procedure previously reported by Akortia et al. (2017), and using DCM for elution. The clean-up column was prepared by packing in layers into Pasteur pipettes $(230 \mathrm{~mm})$ from bottom with a glass wool, silica $(0.16 \mathrm{~g})$, basic silica $(0.16 \mathrm{~g})$, silica (0.16 g), acidic silica (0.16 g), Pesticarb (0.06 g) and finally topped with activated sodium sulphate $(0.5 \mathrm{~g})$ (Akortia et al. 2017). Meanwhile, glass wool separated each layer of the packed material for an enhanced cleaning. After pre-cleaning of the packed column with about $12 \mathrm{~mL}$ toluene/DCM $(1: 1, v / v)$, the sample extracts were loaded before the solvent reached the bed of the column and further eluted with $6 \mathrm{~mL}$ of the solvent mixture. The clean extracts were finally concentrated to incipient dryness under a gentle $\mathrm{N}_{2}$ stream. About $1 \mathrm{~mL}$ of toluene was added to re-constitute the extracts and $\mathrm{N}_{2}$ was bubbled through to make up a final volume of $200 \mu \mathrm{L}$. Thereafter, a known amount of $2.5 \mathrm{ng} \mu \mathrm{L}^{-1}$ internal standard (BDE-118) was added and an aliquot of $1.0 \mu \mathrm{L}$ was injected into the gas chromatography-mass spectrometer (GC-MS) under optimized instrumental conditions.

Analysis was performed by a Shimadzu model 2010 plus gas chromatography coupled with a model QP 2010 ultra-mass spectrometer (Shimadzu, Japan) using electron ionization in the selective ion-monitoring (SIM) mode. One microliter solution of the extracted sample was injected automatically by Shimadzu A0C-20i auto sampler. An Inertcap 5MS/NP capillary column $(30 \mathrm{~m} \times$ $0.25 \mathrm{~mm}$ ID, $0.1 \mu \mathrm{m}$ film thickness) was used for the separation. The oven temperature was programmed as follows: $100{ }^{\circ} \mathrm{C}(1 \mathrm{~min})$, then $15{ }^{\circ} \mathrm{C} \mathrm{min}^{-1}$ to $160{ }^{\circ} \mathrm{C}$ (0 min) and at $30{ }^{\circ} \mathrm{C} \mathrm{min}^{-1}$ to $300{ }^{\circ} \mathrm{C}(0 \mathrm{~min})$ and $10{ }^{\circ} \mathrm{C} \mathrm{min}{ }^{-1}$ to $325{ }^{\circ} \mathrm{C}(3 \mathrm{~min})$. The carrier gas used was helium (purity 99.999\%) and set at a constant flow of $1.5 \mathrm{~mL} \mathrm{~min}{ }^{-1}$. The injector, transfer line and ion source temperatures were set at 225,300 and $250{ }^{\circ} \mathrm{C}$, respectively.

\section{TOC determination}

The analytical procedure employed for the TOC determination was by loss-on-ignition (LOI), and reported in our previous study (Daso et al. 2016). Briefly, the soil samples (pre-weighed) were placed in an oven previously set to about $100{ }^{\circ} \mathrm{C}$ and kept overnight. The samples were subsequently removed and gently placed in the desiccator until each attained the room temperature. The samples were then re-weighed and the amount of moisture present in each sample was determined. Afterwards, the samples were ignited at $450{ }^{\circ} \mathrm{C}$ in a furnace for $5 \mathrm{~h}$ and were allowed to cool to the room temperature in the desiccator. The difference in the mass of the samples before and after the ignition corresponds to the mass of organic carbon present in the samples (Daso et al. 2016). The results were presented as percentage of the organic carbon present.

\section{Particle size distribution}

Portions of each sieved soil aggregates were weighed and analysed with Microtrac S3500 laser particle size analyser in order to further determine the particle size distributions. The Microtrac S3500 uses unique detector geometry and three accurately placed red laser diodes that deliver signals proportional to the volume of particulate material. Briefly, the sample was fed into the dry dispersion device (TURBOTRAC) that works in conjunction with the S3500 laser diffraction system to deliver dispersed samples to the measuring cell in the Microtrac optical bench for consistent and repeatable particle size analysis of dry soil samples (Microtrac S3500 2011). The instrument utilizes a combination of strong vacuum and compressed nitrogen (99.999\%) to disperse the soil particles, and measures particle sizes from 0.02-2800 $\mu \mathrm{m}$ (Microtrac S3500 2011). Detailed statistical information including percentage of particle size in various ranges, peak and distribution curves are acquired from the instrument's software (Microtrac-Flex).

From the data, values of the effective size $\mathrm{D}_{10}$, the size of the screen that would allow only $10 \%$ finer to pass; $\mathrm{D}_{30}, 30 \%$ finer; and $\mathrm{D}_{60}$, diameter corresponding to $60 \%$ finer in the particle size distributions were estimated.

\section{Size selection strategy for soil exposure analysis and risk assessment}

Generally, exposure assessment warrants that the analysed particle size employed should be representative of the soil particles likely to adhere to the skin or could be ingested (Cao et al. 2012). Few reports (Mercier et al. 2011; Cao et al. 2012) suggested that ultra-fine particles adhered better to the skin than coarse particles. Meanwhile, the recommended size fractions for exposure assessments in the literature are inconsistent. For example, some studies postulated that more attention should be 
paid to size fractions less than $100 \mu \mathrm{m}$, and that which is larger than $250 \mu \mathrm{m}$ was not appropriate for exposure assessment (Edwards and Lioy 1999).

In the present study, the soils were sieved to obtain fractions more likely to adhere to the skin (i.e. 150$250 \mu \mathrm{m}$ and $45-150 \mu \mathrm{m})$. In order to evaluate the size selection strategy relevant for soil exposure analysis, PBDE concentrations in the specific soil fractions were estimated using the PBDE concentrations and the weights of the soil in each fraction (Kajiwara and Takigami 2016) as follows:

$$
C_{E s t .}=\frac{\sum C_{f} W_{f}}{\sum W_{f}}
$$

where:

$C_{E s t .}=$ the estimated concentration of PBDEs in a specific size fraction $\left(\mathrm{ng} \mathrm{g}^{-1}\right)$.

$C_{\mathrm{f}}=$ the corresponding concentrations in each size fraction of soil $\left(\mathrm{ng} \mathrm{g}^{-1}\right)$.

$\mathrm{W}_{f}=$ the corresponding weight of soil in each fraction (g).

Herein, we also focused on contaminate concentrations in two cases; case A and B corresponding to each soil size fraction that was evaluated. In this scenario, case A corresponded to the minimum size fraction sieved $(45-150 \mu \mathrm{m})$, whereas case B corresponded to the soil fraction sieved through $150-250 \mu \mathrm{m}$ mesh. Hence, using the minimum fraction as the bench mark (particle size more prone to skin adherence), the percentage difference in concentrations between case A and case B was estimated using the equation below (Kajiwara and Takigami 2016):

$$
\mathrm{C}(\%)=100 \times \frac{C_{\text {caseA }}-C_{\text {caseB }}}{C_{\text {caseA }}}
$$

where $C$ is the difference in concentrations between case A and case B reported in percentage.

\section{Quality assurance/quality control (QA/QC)}

Several quality control procedures were employed in order to achieve a reliable data. All samples were wrapped in aluminium foil. Silica gel, anhydrous sodium sulphate and copper powder were baked in a muffle furnace at $450{ }^{\circ} \mathrm{C}$ for $12 \mathrm{~h}$ prior to use. Glass wool was cleaned by soaking in $n$-hexane and dried in an oven overnight prior to use. Acidic silica and basic silica were prepared following the US EPA method 1614 (USEPA METHOD 1614 2007). All standards and serial dilutions were prepared under the fume hood. Prior to the extraction of the soil samples, extraction efficiencies of acetone, $n$-hexane, toluene and DCM were in combination and as individuals tested by extracting $10 \mathrm{~g}$ of previously activated sodium sulphate. A solvent combination of DCM/toluene $(1: 1, v / v)$ recovered best for most of the target analytes. The extracts were shielded from UV light at all times by keeping them in glass amber bottles. The performance and validation of the method was done through triplicate analysis of organic contaminants in house dust SRM-2585, and the recovery was deemed satisfactory (see Additional file 1: Table S5). The recovery of the surrogate standards ${ }^{13} \mathrm{C}-\mathrm{BDE}-77$ and ${ }^{13} \mathrm{C}-\mathrm{BDE}-139$ varied between $83-111$ and $75-90 \%$, respectively. An initial solvent blank and a laboratory performance standard check (linearity of the calibration curve) were performed using both individual as well as the mixture of the commonly reported brominated flame retardant standards available in order to ensure proper performance of the GC-MS. However, no target compounds were detected in the blanks. The duplicate samples in the laboratory were analysed alongside the regular samples for repeatability and reproducibility. The retention times of the unknown analytes were matched to that of the standards and quantified by monitoring the target and reference ions. The instrument LOD was defined as three times the signal-to-noise ratio and LOQ as ten times signal-to-noise ratio of the lowest detectable concentration of a mixture of standards. The LOD ranged between 0.01 and $0.02 \mathrm{ng} \mu \mathrm{L}^{-1}$, for BDE-28 and BDE-100, respectively.

\section{Statistical analysis}

All descriptive statistics were computed using Microsoft Office Excel 2010 software. A non-parametric test, Wilcoxon signed rank test, was employed to test the hypothesis of the significant difference in the PBDEs concentration among the particle size fractions in the pooled soil samples from the same location, and MannWhitney rank test was used to further investigate the hypothesis that PBDEs concentrations in the size fractions were significantly different. SPSS version 20.0 (IBM SPSS Inc., Chicago, USA) was employed for correlational analysis. The values below the detection limit were treated as zero during statistical analysis. An association with a $p$ value $<0.05$ or less was considered statistically significant.

\section{Results and discussion}

\section{Concentration of PBDEs with respect to particle sizes}

The total concentration of the $\Sigma_{7}$ PBDEs detected in the soil samples with respect to the particle sizes in the present study are presented in Table 1. It can be inferred from Table 1 that the quantities of PBDEs in each sieved soil aggregate, as well as their ranges, were similar. This is possibly due to the sequential sieving and accumulation of the PBDE congeners in the soil aggregates. 
Table 1 Summary of total concentrations $(\Sigma)\left(\mathrm{ng} \mathrm{g}^{-1}\right) \mathrm{dw}$ of PBDEs in soil samples with respect to particle sizes

\begin{tabular}{lllll}
\hline Samples & $\sum_{7}$ PBDE concentrations $\left(\mathrm{ng} \mathrm{g}^{-1}\right)$ & & & \\
\cline { 2 - 5 }$n=6$ & $\sum_{7}$ PBDE $(150-250 \mu \mathrm{m})$ & Range & $\sum_{7}$ PBDE $(45-150 \mu m)$ & Range \\
\hline S1 & 7.08 & ND-1.96 & 7.01 & ND-1.98 \\
S2 & 7.57 & ND-1.99 & 7.68 & ND-1.98 \\
S3 & 7.12 & ND-1.97 & 7.13 & ND-1.98 \\
S4 & 10.8 & $0.394-2.49$ & 7.29 & ND-1.98 \\
S5 & 9.22 & $0.132-2.11$ & 8.77 & $0.266-1.99$ \\
S6 & 7.93 & $0.397-1.98$ & 7.27 & ND-1.98 \\
\hline
\end{tabular}

$\Sigma_{7} \mathrm{PBDE}=$ total of seven BDE congeners analysed in each sample; $n=$ pooled samples; $N D$ not detected

However, the descriptive statistics showing the mean, median, minimum and maximum concentrations as well as the $\sum_{7}$ PBDEs in the samples analysed were also provided in the Additional file 1: (Tables S1 and S2).

The total concentrations of the $\sum_{7}$ PBDEs ranged between 7.08 and $12.3 \mathrm{ng} \mathrm{g}^{-1}$ with an overall median of $7.32 \mathrm{ng} \mathrm{g}^{-1}$, and also between 7.00 and $8.77 \mathrm{ng} \mathrm{g}^{-1}$ with an overall median of $7.21 \mathrm{ng} \mathrm{g}^{-1}$, corresponding to size fractions $150-250 \mu \mathrm{m}$ and $45-150 \mu \mathrm{m}$, respectively, (see Additional file 1: Tables S1 and S2 ).

BDE-183 was the predominant congener in all samples, and ranged between 1.97 and $2.11 \mathrm{ng} \mathrm{g}^{-1}$ with a median value of $1.98 \mathrm{ng} \mathrm{g}^{-1}$ in the $150-250 \mu \mathrm{m}$ size fractions, and also ranged between 1.98 and $1.99 \mathrm{ng} \mathrm{g}^{-1}$ with a median of $1.98 \mathrm{ng} \mathrm{g}^{-1}$ in the $45-150 \mu \mathrm{m}$ size fractions.

The box plots illustrating the summary of $\sum_{7} \mathrm{PBDE}$ concentrations for the size fractions 150-250 $\mu \mathrm{m}$ and $45-150 \mu \mathrm{m}$ are shown in Figs. 2 and 3, respectively.

As presented in Figs. 2 and 3, the median values varied from 0.0659 to $1.98 \mathrm{ng} \mathrm{g}^{-1}$ dry weight ( $\mathrm{dw}$ ) corresponding to $150-250 \mu \mathrm{m}$ size fraction, and from below detection limit (BDL) to $1.98 \mathrm{ng} \mathrm{g}^{-1}$ for the $45-150 \mu \mathrm{m}$ size fraction. According to the literature, contaminant concentrations in soil aggregates tend to increase as particle size decreases (Mercier et al. 2011); meanwhile, PBDE concentrations in particles representing 45-150 $\mu \mathrm{m}$ size deviated slightly from this hypothesis, possibly due to aggregation and the consequence of dry sieving. This implied that the PBDE compounds preferentially adhered to the preceding soil aggregates with a larger specific surface area, while the presence of abrasion particles from different kinds of PBDE-treated products which could be retained by the preceding sieve may have enhanced the concentration of the target chemicals in the 150-250 $\mu \mathrm{m}$ aggregates. Thus, direct leaching of PBDEs into soil from electronic and domestic consumer items could be possible. This observation was confirmed in previous studies by Osako et al. (2004) and Kiddee et al. (2013). According to the literature, semi-volatile organic compounds (SVOCs) such as BFRs are not often homogeneously distributed in soil or dust (Cao et al. 2013). What is more, the distribution patterns of PBDEs in soil with respect to particle size can also be influenced by possible fragmentation and absorption processes (Cao

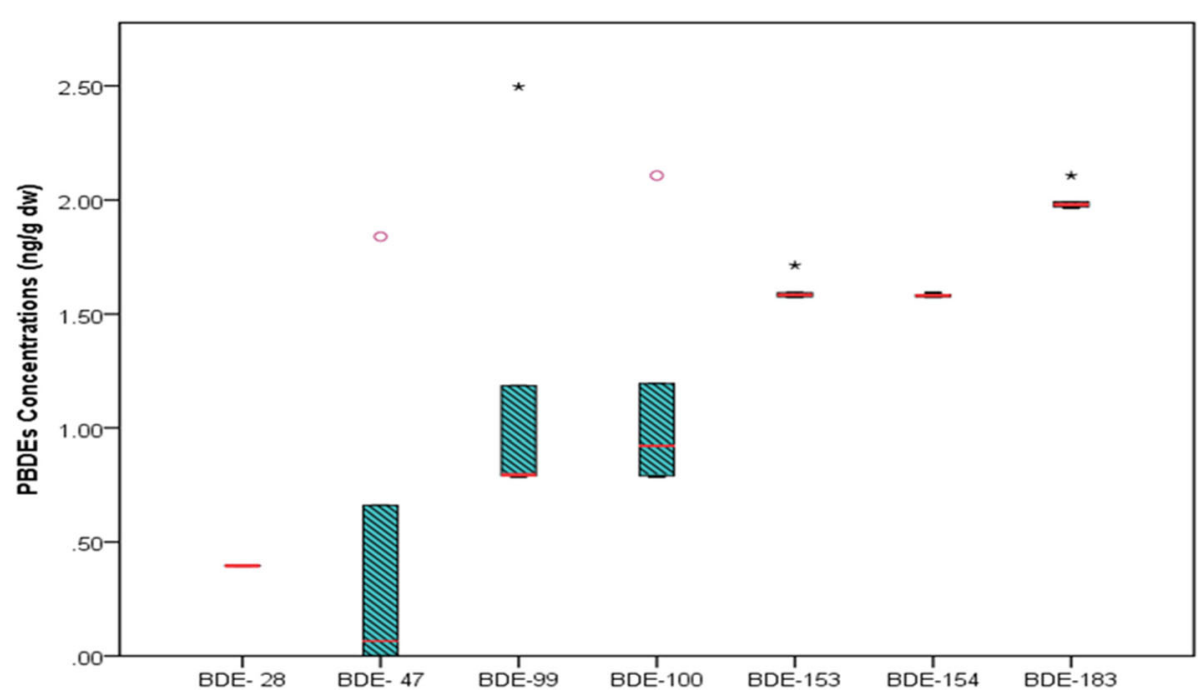

Fig. 2 Box plots of $\sum_{7}$ PBDE concentrations in landfill soils $(n=6)$; the horizontal line and low and upper edges of the box represent the median values and the 25th and 75th percentiles, respectively, in particles 150-250 $\mu \mathrm{m}$ fractions. Points outside the range show up as outliers 


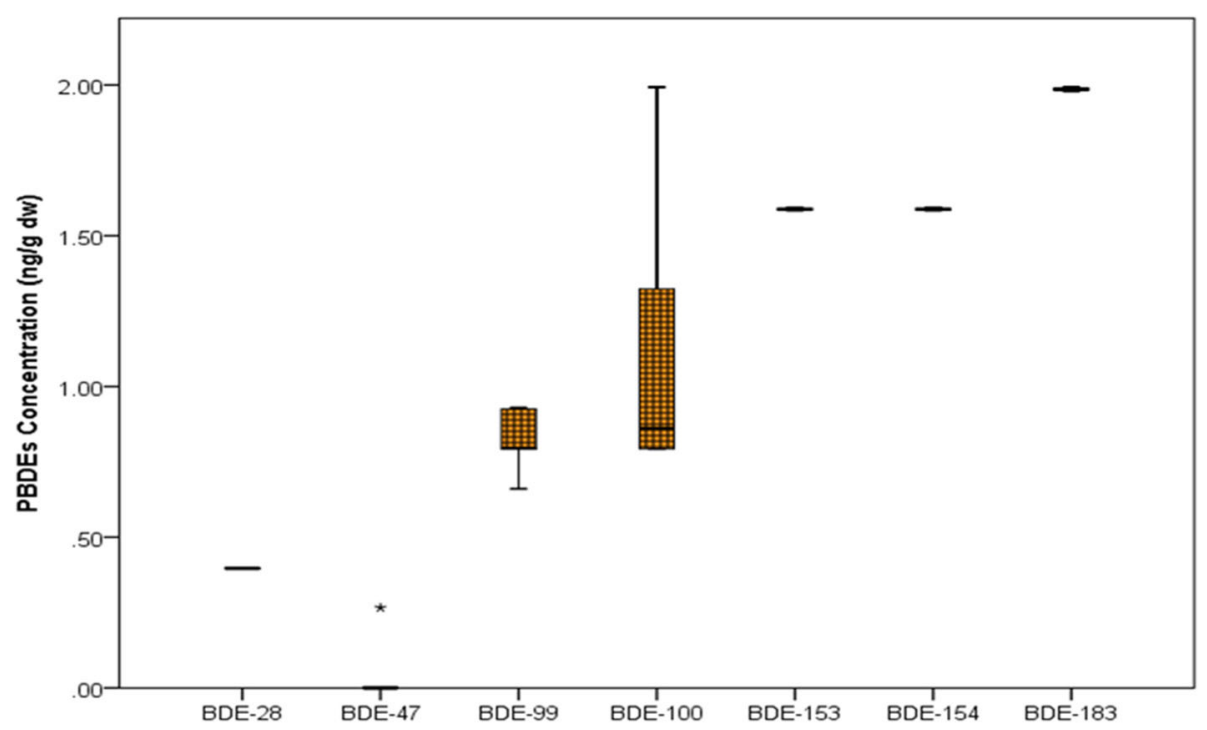

Fig. 3 Box plots of $\sum_{7} P B D E$ concentrations in landfill soils $(n=6)$; the horizontal line and low and upper edges of the box represent the median values, the 25th and 75th percentiles, respectively, in particles $45-150 \mu \mathrm{m}$ fractions. Points outside the range show up as outliers

et al. 2013). Typically, it is expected that the concentration of PBDEs in the soil size fractions with a larger specific surface area $(150-250 \mu \mathrm{m})$ and exposure possibility would be more. Additionally, the slightly lower concentrations found in the $45-150 \mu \mathrm{m}$ soil fractions may be attributed to the smaller quantity of the sequentially sieved soil used and hence, its smaller specific surface area. Despite the small quantity of the $45-150 \mu \mathrm{m}$ fractions, the median concentrations obtained for both size fractions were similar. Meanwhile, it still remains unclear about the underlying mechanism that the concentration of toxic chemicals increase as soil particle size decrease, and specific surface area is often presumed to be the likely determinant, although theoretical and experimental proofs are lacking. Therefore, the present results should be interpreted with caution because of the small sample size used. Nonetheless, some previous investigations (Cao et al. 2012, 2013; Harrad and Abdallah 2011) supported the validity of our findings.

Generally, the reported PBDE levels in the present study were lower than that reported elsewhere such as the ewaste recycling site in south China (77.3-249 $\mathrm{ng} \mathrm{g}^{-1}$ ) (Wang et al. 2011). However, it should be noted that higher concentrations of PBDEs reported from e-waste sites could be attributed to point source pollution characteristics rather than dilution effects from mixed waste on landfill sites. Meanwhile, the reported PBDE levels in the present study were in similar range as the one reported from the Netherlands (14-22 $\mathrm{ng} \mathrm{g}^{-1}$ ) (Verslycke et al. 2005), and approximately two orders of magnitude higher than those from Korea $\left(0.05-0.90 \mathrm{ng} \mathrm{g}^{-1}\right.$ ) (Moon et al. 2007), and Japan (0.051-3.6 $\mathrm{ng} \mathrm{g}^{-1}$ ) (Minh et al. 2007).
As presented in Table 1 as well as in Figs. 2 and 3, the concentrations detected in both soil aggregates were relatively similar; about $51 \%$ except for sample S4 (recycling area) which was in the $150-250 \mu \mathrm{m}$ size fractions. However, Wei et al. (2009) reported over $80 \%$ of $\Sigma_{13}$ PBDEs in settled dust particle size fractions between 150 and $250 \mu \mathrm{m}$, while Kefeni and Okonkwo (2014) also reported about $93.4 \%$ of PBDEs in dust fractions less than $150 \mu \mathrm{m}$. Based on these earlier findings, it is essential that more attention should be paid to soil fractions in the range $150-250 \mu \mathrm{m}$ in diameter or less. Besides, it is also important to note that due to different sources as well as the chemical/physical properties of toxic chemicals, and the inconsistency in characterizing soil size fractions across sections, it is imperative that various size fractions be harmonized in order to derive more accurate or comparable exposure risk assessment results from chemically contaminated soils. From the present results, it is also possible to recommend that total toxicant determinations should be limited to particle sizes in the region of $250 \mu \mathrm{m}$ or lesser. Thus, size fractions containing coarse particles which may or not bear targeted contaminants could significantly compromise exposure estimates.

\section{Percentage composition and possible sources of BDE congeners}

Comparing the composition profiles of individual BDE congeners, it became obvious that the octa-BDE marker (BDE-183) contributed more to the total congener concentrations in both $150-250 \mu \mathrm{m}$ and $45-150 \mu \mathrm{m}$ size fractions (ca $18.5-27.7 \%$ and $22.7-28.3 \%$, respectively), while the percentage compositions of BDEs (-153 and 
-154) contributed approximately 20 and $21 \%$ each in the $150-250 \mu \mathrm{m}$ and $45-150 \mu \mathrm{m}$ size fractions, respectively (Fig. 4).

The relative abundance of BDE-153 and BDE-154 in both size fractions was quite pronounced. However, it is not clear as to their slightly enhanced contribution (ca $1 \%)$ in the $45-150 \mu \mathrm{m}$ fraction. This suggested sources from major components of the commercial penta-BDE which has been used in automotive polyurethane seating foams and textiles (Gaylor et al. 2012; Vyzinkarova and Brunner 2013). BDE-183, the predominant congener, may be attributed to the source contribution from octaBDE commercial formulation, mainly used in acrylonitrile-butadiene-styrene (ABS) for casings of electrical and electronic equipment (EEE) and some office equipment such as printers and photocopiers (UNEP 2010a, 2010b). Therefore, the congener profiles of the soils in this study (Fig. 4) showed more enrichment by penta-BDEs and octa-BDEs, which might have leached out of PBDE-treated materials into the landfill soil through abrasion or fragmentation process (Cao et al. 2014).

\section{Relationship between TOC and $\Sigma$ PBDEs with different particle sizes}

The TOC contents of the soil ranged between 3.97 and $7.27 \%$, with an average of $5.29 \pm 1.23 \%$. Figure 5 shows the linear regression of the TOC and $\Sigma$ PBDEs in the different size fractions.

Spearman's rank correlation test was used to evaluate the relationship between the $\Sigma_{7} \mathrm{PBDEs}$ concentration and TOC with respect to both size fractions. As presented in Fig. 5, a positive correlation was observed between $\Sigma_{7} \mathrm{PBDEs}$ and the TOC with statistical significance $\left(r^{2}=\right.$ $0.829, p<0.05)$ for particle sizes ranging between 150 and
$250 \mu \mathrm{m}$. Meanwhile, a non-significant correlation was observed for size fractions ranging between 45 and $150 \mu \mathrm{m}$ $\left(r^{2}=0.771, p>0.05\right)$. These findings were however, comparable to those found in previous studies (Wu et al. 2013; Yuan et al. 2012).

It is worth noting that the coefficient of determination $r^{2}$ for the $150-250 \mu \mathrm{m}$ size fraction was greater than that for the $45-150 \mu \mathrm{m}$ fraction, which suggested that the $150-250 \mu \mathrm{m}$ size fractions correlated well with the organic carbon content of the soil. It became obvious that there was a linear proportionality in the relationship between the TOC and $\Sigma_{7}$ PBDEs with respect to the size fractions. This indicated that TOC could be influential, but not determinant of the distribution of PBDEs in the soils. Ideally, other factors such as specific surface area (Cao et al. 2012) and physico-chemical properties of the individual BDE congeners could also affect their behaviour in soil, although more detailed research is required to further elucidate this relationship.

Meanwhile, the information derived from the TOC and particle sizes alone could not be definitive to some extent. There could be other competing factors such as black carbon (Ali et al. 2015) and clay minerals (Yuan et al. 2012), which have also been known to somewhat govern the distribution of POPs such as PBDEs in soil.

\section{Soil particle size distribution using particle size analyser}

Further analysis of the soil particle size distribution was done using a particle size analyser (Microtrac S 3500) in order to distinguish the particle sizes that would ordinarily not be quantified using the mechanical sieves, and the summary of the results presented as semilogarithmic plots; see (Additional file 1: Figure S1). For the purpose of quantifying the particle sizes that would be prone to adhering to the skin, the estimated values
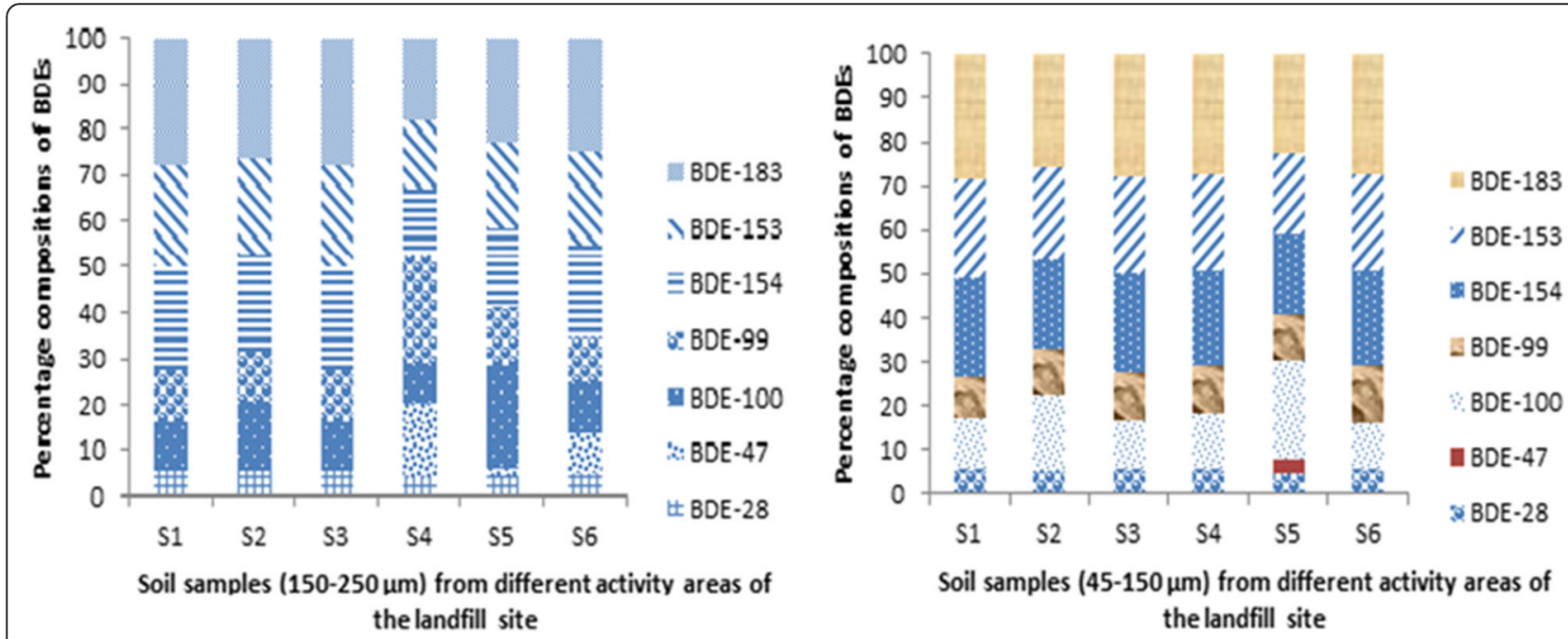

Fig. 4 Composition profiles of PBDE congeners from different activity areas for particle sizes 150-250 $\mu \mathrm{m}$ and 45-150 $\mu \mathrm{m}$, respectively 

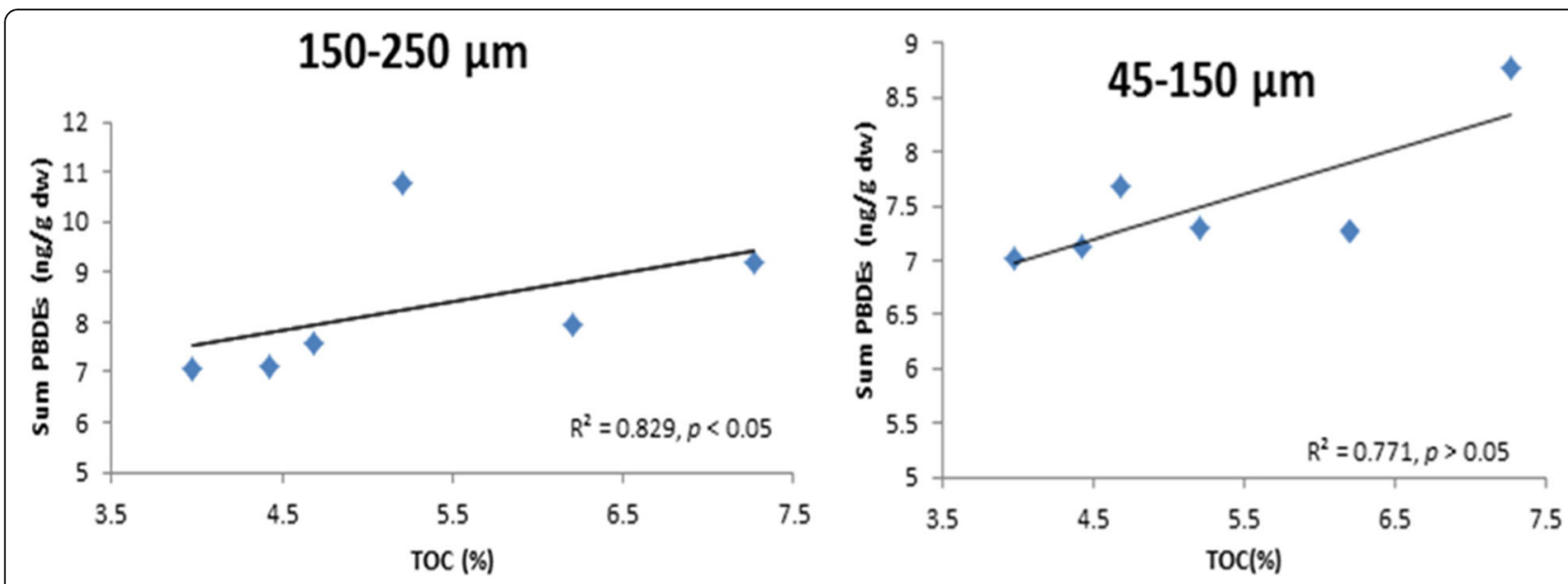

Fig. 5 Correlation between TOC and concentration of $\sum_{7}$ PBDES

corresponding to $D_{10}, D_{30}$ and $D_{60}$ for the soil samples using S1 (Additional file 1: Figure S1) as an example, were 15.6, 31.1 and $62.2 \mu \mathrm{m}$, respectively. In the present study, it became obvious that soil particle sizes determined using solely the mechanical sieves could not give a complete distribution of the particle sizes. Therefore, it is possible that the mechanical sieves enhanced weak Van der Waals attractive forces or London dispersion forces which could affect the soil particles during dry sieving (Kefeni and Okonkwo 2014). In effect, some of the soil particles could stick to one another and not be able to pass through the mesh effectively. As a result, some deviations were expected from mass losses during dry sieving which could not be quantified due to error from adherence on the surface of the mechanical sieves.

On the contrary, for the particle size analyser, inert gas and strong vacuum system was used coupled with a measurable particle diameter range of 0.02$2800 \mu \mathrm{m}$ (Microtrac S3500 2011). Thus, adherence of soil particles to each other could be evaded, which gave the particle size analyser an edge over the mechanical sieves used in soil size fractionation for exposure risk assessment.

\section{Particle size selection strategy for soil exposure analysis}

In order to determine the size selection strategy for soil exposure analysis, the PBDEs in the soil size fractions were estimated using the concentrations and the weight of the soils in each size fraction using Eq. 1. Therefore, the $C_{E s t}$ for soil size fraction $150-250 \mu \mathrm{m}$ was $49.7 \mathrm{ng} \mathrm{g}^{-1}$ and that for the $45-150 \mu \mathrm{m}$ was $45.1 \mathrm{ng} \mathrm{g}^{-1}$. The detailed information on the estimation can be found in the Additional file 1.

The estimated results by means of Eq. 2 showed that the concentration of PBDEs was about 10\% more in the $150-250 \mu \mathrm{m}$ soil size fractions (i.e. case B) than in the $45-150 \mu \mathrm{m}$ fractions (i.e. case A) (see Additional file 1:
Tables S3 and S4). The slight concentration difference may be attributed to the reduced quantity of the 45$150 \mu \mathrm{m}$ fractions used in the chemical analysis. Although, it was obvious that slightly high amounts of PBDEs were found in particle size fractions between 150 and $250 \mu \mathrm{m}$ (Table 1), the mesh size employed for sample preparation in the present study may have little effect on the concentration of toxic chemicals as long as ultra-fine fractions are inclusive. This assertion also concurred with some previous studies (Cao et al. 2012; Kajiwara and Takigami 2016). Nonetheless, targeted PBDE compounds in the present study were detected in soil particle sizes between 250 and $45 \mu \mathrm{m}$, suggesting that the soil particles that were prone to adhering efficiently to the skin with greater exposure potential were associated with fine particles.

More so, a previous study in Japan (Yamamoto et al. 2006) showed that the actual size distribution of soil particles mostly adherent to children's hands after outdoor playing activities were between 200 and $300 \mu \mathrm{m}$ in size, with a mode diameter of $39 \pm 26 \mu \mathrm{m}$. Similarly, Choate et al. (2006a, 2006b) concluded that only soil particles with size fractions $<63 \mu \mathrm{m}$ adhered to the skin. Conversely, possible PBDEs in the coarser fractions (not analysed in this study) could not be ruled out. Therefore, in interpreting results of toxic chemicals in soil with respect to particle size, it would be apt to consider soil or dust fractions less than $200 \mu \mathrm{m}$, and also further research is needed to globally characterize soil samples into respirable and inhalable size fractions in an effort to assess exposure risk more accurately.

\section{Conclusions}

The present study evaluated the effect of particle size on the distribution of PBDEs in landfill soils and the selection of soil fraction that could influence exposure risk assessment. Regression analysis and Spearman's rank 
correlation test were applied to test the relationship between concentrations of PBDEs in each size fraction and the organic carbon contents of the soil. The coefficient of determination $r^{2}$ indicated that there was a linear proportionality in the relationship between the TOC and $\Sigma_{7}$ PBDEs in the soil. PBDEs were also found to be slightly pronounced in the $150-250 \mu \mathrm{m}$ soil fractions. Only less than $10 \%$ of the PBDE compounds were distributed in the $45-150 \mu \mathrm{m}$ particles. The observed variation in the concentration of PBDEs reported for both size fractions showed that selection of soil size fraction can be a critical influencing factor which may have an impact on exposure assessment results. Based on the concentration profiles of PBDEs in the present study, it was possible to recommend that more attention should be paid to particles less than $250 \mu \mathrm{m}$ in diameter. More so, it became obvious in the present study that determining soil size fractions using a particle size analyser could give more detailed information than relying solely on mechanical sieves. Based on this assertion, it was recommended that inter-laboratory study campaigns be promoted in order to appropriately characterize soil size fractions prone to high exposure as well as support epidemiological study conclusions.

\section{Additional file}

Additional file 1: Table S1. Descriptive statistics of PBDE quantities (ng $\mathrm{g}^{-1}$ ) in the landfill soils (150-250 $\mu \mathrm{m}$ fractions). Table S2. Descriptive statistics of PBDE quantities $\left(\mathrm{ng} \mathrm{g}^{-1}\right)$ in the landfill soils $(45-150 \mu \mathrm{m}$ fractions). Table S3. PBDEs load in sieved soil 150-250 $\mu \mathrm{m}$. Table S4. PBDEs load in sieved soil 45-150 $\mathrm{\mu m}$. Table S5. Certified and measured concentrations $\left(\mathrm{ng} \mathrm{g}^{-1}\right.$ ) of certified reference material (NIST SRM 2585Organic contaminants in house dust). Figure S1. Particle size distribution in landfill site soils using Microtrac S3500 particle size analyser. (DOCX $242 \mathrm{~kb}$ )

\section{Abbreviations}

BDE: Brominated diphenyl ether; FR: Flame retardant; GC-MS: Gas chromatography-mass spectrometer; PBDE: Polybrominated diphenyl ether; POP: Persistent organic pollutant; SVOC: Semi-volatile organic compound; TOC: Total organic carbon

\section{Acknowledgements}

The authors express their gratitude to the Tshwane University of Technology for the bursary support and the enabling environment for this study. We wish to thank all persons who offered support during the sampling and analysis of data, especially, Dr. O.I. Olukunle and Dr. Charles Gyamfi, formerly of the Tshwane University of Technology.

\section{Authors' contributions}

This work was designed by EA, ML and JOO. The experimental work and analysis of the results were carried out by EA, ML and JOO. This manuscript was written by EA and JOO. All authors read and approved the final manuscript.

\section{Funding}

This research did not receive any specific grant from funding agencies in the public, commercial, or not-for-profit sectors. However, this research was partly conducted with the support of a postgraduate student bursary from the Faculty of Science, Tshwane University of Technology.

\section{Availability of data and materials}

All data generated or analysed during this study are included in this published article and its Additional file 1.

\section{Competing interests}

The authors declare that they have no competing interests.

Received: 4 February 2019 Accepted: 30 May 2019

Published online: 11 June 2019

\section{References}

Akortia E, Olukunle OI, Daso AP, Okonkwo JO. Soil concentrations of polybrominated diphenyl ethers and trace metals from an electronic waste dump site in the Greater Accra region, Ghana: implications for human exposure. Ecotoxicol Environ Saf. 2017;137:247-55. https://doi.org/10.1016/j. ecoenv.2016.12.008.

Ali U, Mahmood A, Syed JH, Li J, Zhang G, Katsoyiannis A, Jones KC, Malik RN. Assessing the combined influence of TOC and black carbon in soil-air partitioning of PBDEs and DPs from the Indus River Basin, Pakistan. Environ Pollut. 2015;201:131-40. https://doi.org/10.1016/j.envpol.2015.02.035.

Athanasiadou M, Cuadra SN, Marsh G, Bergman A, Jakobsson K. Polybrominated diphenyl ethers (PBDEs) and bioaccumulative hydroxylated PBDE metabolites in young humans from Managua, Nicaragua. Environ Health Perspect. 2008; 116:400-8.

Bergman Å, Rydén A, Law RJ, de Boer J, Covaci A, Alaee M, et al. A novel abbreviation standard for organobromine, organochlorine and organophosphorus flame retardants and some characteristics of the chemicals. Environ Int. 2012;49:57-82. https://doi.org/10.1016/j.envint. 2012.08.003.

Cao Z, Xu F, Covaci A, Wu M, Wang H, Yu G, Wang B, Deng S. Distribution patterns of brominated, chlorinated and phosphorous flame retardants with particle size in indoor and outdoor dust and implications for human exposure. Environ Sci Technol. 2014;48:8839-46.

Cao ZG, Yu G, Chen Y, Liu C, Liu K, Zhang T, Wang B, Deng S, Huang J. Mechanisms influencing the BFR distribution patterns in office dust and implications for estimating human exposure. J Hazard Mater. 2013;252-253: $11-8$.

Cao ZG, Yu G, Chen YS, Cao QM, Fiedler H, Deng SB, Huang J, Wang B. Particle size: a missing factor in risk assessment of human exposure to toxic chemicals in settled indoor dust. Environ Int. 2012;49:24-30. https://doi.org/ 10.1016/j.envint.2012.08.010.

Cetin B, Odabasi M. Particle-phase dry deposition and air-soil gas-exchange of polybrominated diphenyl ethers (PBDEs) in Izmir, Turkey. Environ Sci Technol. 2007:41:4986-92. https://doi.org/10.1021/es070187v.

Choate LM, Ranville JF, Bunge AL, Macalady DL. Dermally adhered soil: 1. Amount and particle-size distribution. Integr Environ Assess Manag. 2006a;2: 375-84. https://doi.org/10.1002/ieam.5630020409.

Choate LM, Ranville JF, Bunge AL, Macalady DL. Dermally adhered soil: 2. Reconstruction of dry-sieve particle-size distributions from wet-sieve data. Integr Environ Assess Manag. 2006b;2:385-90. https://doi.org/10.1002/ieam. 5630020410

Cousins IT, Beck AJ, Jones KC. A review of the processes involved in the exchange of semi-volatile organic compounds (SVOC) across the air-soil interface. Sci Total Environ. 1999;228:5-24. https://doi.org/10.1016/S00489697(99)00015-7.

Danon-Schaffer MN (2010) Polybrominated diphenyl ethers in landfills from electronic waste. PhD. Thesis, University of British Columbia, Canada. doi: https://doi.org/10.14288/1.0058694.

Danon-Schaffer MN, Mahecha-Botero A, Grace JR, Ikonomou M. Mass balance evaluation of polybrominated diphenyl ethers in landfill leachate and potential for transfer from e-waste. SciTotal Environ. 2013;461:290-301. https://doi.org/10.1016/j.scitotenv.2013.03.080.

Daso AP, Akortia E, Okonkwo JO. Concentration profiles, source apportionment and risk assessment of polycyclic aromatic hydrocarbons (PAHs) in dumpsite soils from Agbogbloshie e-waste dismantling site, Accra, Ghana. Environ Sci Pollut Res. 2016;23:10883-94. https://doi.org/10.1007/s11356-016-6311-3.

Daso AP, Fatoki OS, Odendaal JP, Olujimi OO. Occurrence of selected polybrominated diphenyl ethers and 2,2',4,4',5,5'-hexabromobiphenyl (BB153) in sewage sludge and effluent samples of a wastewater-treatment plant in Cape Town, South Africa. Arch Environ Contam Toxicol. 2012;62:391-402. https://doi.org/10.1007/s00244-011-9720-9. 
Dušek L, Sáňka M, Hofman J, Čupr P, Jarkovský J, Zbíral J, Klánová J. Soil burdens of persistent organic pollutants - their levels, fate and risk. Part I. variation of concentration ranges according to different soil uses and locations. Environ Pollut. 2009;157:3207-17. https://doi.org/10.1016/j.envpol.2009.05.031.

Edwards RD, Lioy PJ. The EL sampler: a press sampler for the quantitative estimation of dermal exposure to pesticides in housedust. J Expo Anal Environ Epidemiol. 1999;9:521-9.

Frederiksen M, Vorkamp K, Thomsen M, Knudsen LE. Human internal and external exposure to PBDEs - a review of levels and sources. Int J Hyg Environ Health. 2009;212:109-34

Gaylor MO, Harvey E, Hale RC. House crickets can accumulate polybrominated diphenyl ethers (PBDEs) directly from polyurethane foam common in consumer products. Chemosphere. 2012;86:500-5. https://doi.org/10.1016/j. chemosphere.2011.10.014

Gustafsson O, Haghseta F, Chan C, MacFarlane J, Gschwend PM. Quantification of the dilute sedimentary soot phase: implications for PAH speciation and bioavailability. Environ Sci Technol. 1996;31(1):203-9. https://doi.org/10.1021/ ES960317S.

Harrad S, Abdallah MAE. Brominated flame retardants in dust from UK carswithin-vehicle spatial variability, evidence for degradation and exposure implications. Chemosphere. 2011;82:1240-5.

Johnson-Restrepo B, Kannan K. An assessment of sources and pathways of human exposure to polybrominated diphenyl ethers in the United States. Chemosphere. 2009;76(4):542-8.

Jones-Otazo HA, Clarke JP, Diamond ML, Archbold JA, Ferguson G, Harner T, Richardson GM, Ryan JJ, Wilford B. Is house dust the missing exposure pathway for PBDEs? An analysis of the urban fate and human exposure to PBDEs. Environ Sci Technol. 2005;39:5121-30.

Kajiwara N, Takigami H. Particle size distribution of brominated flame retardants in house dust from Japan. Emerging Contaminants. 2016;2:109-17. https:// doi.org/10.1016/j.emcon.2016.03.005.

Kefeni KK, Okonkwo JO. Distribution of polybrominated diphenyl ethers and dust particle size fractions adherent to skin in indoor dust, Pretoria, South Africa. Environ Sci Pollut Res. 2014;21:4376-86. https://doi.org/10.1007/s11356-0132312-7

Kiddee P, Naidu R, Wong MH. Metals and polybrominated diphenyl ethers leaching from electronic waste in simulated landfills. J Hazard Mater. 2013; 252:243-9. https://doi.org/10.1016/j.jhazmat.2013.03.015.

Lewis RG, Fortune CR, Willis RD, Camann DE, Antley JT. Distribution of pesticides and polycyclic aromatic hydrocarbons in house dust as a function of particle size. Environ Health Perspect. 1999;107:721-6.

Liu W, Li W, Hu J, Ling X, Xing B, Chen J, Tao S. Sorption kinetic characteristics of polybrominated diphenyl ethers on natural soils. Environ Pollut. 2010;158(9): 2815-20. https://doi.org/10.1016/j.envpol.2010.06.021.

Lorber M. Exposure of Americans to polybrominated diphenyl ethers. J Expos Sci Environ Epidemiol. 2008;18:2-19.

Mandalakis M, Besis A, Stephanou EG. Particle-size distribution and gas-particle partitioning of atmospheric polybrominated diphenyl ethers in urban areas of Greece. Environ Pollut. 2009;157:1227-33.

Mercier F, Glorennec P, Thomas O, Bot BL. Organic contamination of settled house dust, a review for exposure assessment purposes. Environ Sci Technol. 2011;45:6716-27. https://doi.org/10.1021/es200925h.

Microtrac S3500 (2011). Tri-laser system, particle size analyser. http://www. microtrac.com. Accessed 28 June 2016.

Minh NH, Isobe T, Ueno D, Matsumoto K, Mine M, Kajiwara N, Takahashi S, Tanabe S. Spatial distribution and vertical profile of polybrominated diphenyl ethers and hexabromocyclododecanes in sediment core from Tokyo Bay, Japan. Environ Pollut. 2007;148:409-17. https://doi.org/10.1016/j.envpol.2006.12.011.

Moon H-B, Kannan K, Lee S-J, Choi M. Polybrominated diphenyl ethers (PBDEs) in sediment and bivalves from Korean coastal waters. Chemosphere. 2007;66: 243-51. https://doi.org/10.1016/j.chemosphere.2006.05.025.

Morawska, L., Salthammer, T. (2003). Indoor environment: airborne particles and settled dust. Wiley-VCH.

Nam JJ, Gustafsson O, Kurt-Karakus P, Breivik K, Steinnes E, Jones KC. Relationships between organic matter, black carbon and persistent organic pollutants in European background soils: implications for sources and environmental fate. Environ Pollut. 2008;156:809-17. https://doi.org/10.1016/j. envpol.2008.05.027.

Odusanya DO, Okonkwo JO, Botha B. Polybrominated diphenyl ethers (PBDEs) in leachates from selected landfill sites in South Africa. Waste Manag. 2009:29: 96-102. https://doi.org/10.1016/j.wasman.2008.02.011.
Olukunle Ol, Okonkwo OJ, Sha'ato R, Wase GA. Levels of polybrominated diphenyl ethers in indoor dust and human exposure estimates from Makurdi, Nigeria. Ecotoxicol Environ Saf. 2015;120:394-9. https://doi.org/10.1016/j. ecoenv.2015.06.023.

Osako M, Kim YJ, Sakai SI. Leaching of brominated flame retardants in leachate from landfills in Japan. Chemosphere. 2004;57:1571-9. https://doi.org/10. 1016/j.chemosphere.2004.08.076.

Pignatello JJ. Soil organic matter as a nanoporous sorbent of organic pollutants. Adv Colloid Interf Sci. 1998;76:445-67. https://doi.org/10.1016/S00018686(98)00055-4.

Semple KT, Riding MJ, McAllister LE, Sopena-Vazquez F, Bending GD. Impact of black carbon on the bioaccessibility of organic contaminants in soil. J Hazard Mater. 2013;261:808-16. https://doi.org/10.1016/j.jhazmat.2013.03.032.

Someya M, Ohtake M, Kunisue T, Subramanian A, Takahashi S, Chakraborty P, Ramachandran $\mathrm{R}$, Tanabe S. Persistent organic pollutants in breast milk of mothers residing around an open dumping site in Kolkata, India: specific dioxin-like PCB levels and fish as a potential source. Environ Int. 2010;36:2735. https://doi.org/10.1016/j.envint.2009.09.003.

UNEP. 2010a. The sixth meeting of the POPs review committee. United Nations Environment Programme. Stockholm Convention on Persistent Organic Pollutants, 11-15 October 2010, Geneva, Switzerland. Geneva. http://chm. pops.int/. Accessed 15 June 2015.

UNEP. 2010b. Supporting document for technical review of the implications of recycling commercial penta and octa-BDE. Stockholm convention document for 6th POP reviewing committee meeting. Geneva. http://chm.pops.int/ Convention/. Accessed 10 March 2016.

USEPA METHOD 1614. (2007). Brominated diphenyl ehters in wate, soil, sediment and tissue by HRGC/HRMS. United States Environmental Protection Agency, Washington, DC. Washington DC.

Verslycke TA, Vethaak AD, Arijs K, Janssen CR. Flame retardants, surfactants and organotins in sediment and mysid shrimp of the Scheldt estuary (the Netherlands). Environ Pollut. 2005;136:19-31. https://doi.org/10.1016/j.envpol. 2004.12.008.

Vyzinkarova D, Brunner PH. Substance flow analysis of wastes containing polybrominated diphenyl ethers. J Ind Ecol. 2013;17:900-11. https://doi.org/ 10.1111/jiec.12054.

Wang G, Peng J, Xu X, Zhang D, Li X. Polybrominated diphenyl ethers in sediments from the southern Yellow Sea: concentration, composition profile, source identification and mass inventory. Chemosphere. 2016;144:2097-105. https://doi.org/10.1016/j.chemosphere.2015.10.088.

Wang Y, Luo C, Li J, Yin H, Li X, Zhang G. Characterization of PBDEs in soils and vegetations near an e-waste recycling site in South China. Environ Pollut. 2011;159:2443-8. https://doi.org/10.1016/j.envpol.2011.06.030.

Weber R, Watson A, Forter M, Oliaei F. Review article: persistent organic pollutants and landfills - a review of past experiences and future challenges. Waste Manag Res. 2011;29:107-21. https://doi.org/10.1177/ $0734242 \times 10390730$.

Wei H, Turyk M, Cali S, Dorevitch S, Erdal S, Li A. Particle size fractionation and human exposure of polybrominated diphenyl ethers in indoor dust from Chicago. J Environ Sci Health Part A. 2009:44:1353-61. https://doi.org/10. 1080/10934520903213251.

Wu MH, Tang L, Xu G, Ma J, Liu N, Wang L, Lei JQ. Polybrominated diphenyl ethers in surface sediments from principal watersheds of Shanghai, China: levels, distribution, influencing factors, and risk assessment. Environ Sci Pollut Res. 2013;20:2651-60. https://doi.org/10.1007/s11356-012-1163-y.

Yamamoto N, Takahashi Y, Yoshinaga J, Tanaka A, Shibata Y. Size distributions of soil particles adhered to children's hands. Arch Environ Contam Toxicol. 2006;51:157-63. https://doi.org/10.1007/s00244-005-7012-y.

Yuan G-L, Xie W, Che X-C, Han P, Liu C, Wang G-H. The fractional patterns of polybrominated diphenyl ethers in the soil of the central Tibetan plateau, China: the influence of soil components. Environ Pollut. 2012;170:183-9. https://doi.org/10.1016/j.envpol.2012.07.011.

Zhang S, Xu X, Wu Y, Ge J, Li W, Huo X. Polybrominated diphenyl ethers in residential and agricultural soils from an electronic waste polluted region in South China: distribution, compositional profile, and sources. Chemosphere. 2014;102:55-60. https://doi.org/10.1016/j.chemosphere.2013.12.020.

\section{Publisher's Note}

Springer Nature remains neutral with regard to jurisdictional claims in published maps and institutional affiliations. 